\title{
Pengembangan Media MONORAJA (Monopoli Aksara Jawa) untuk Siswa Sekolah Dasar
}

\section{Maulia Syahbarina}

PGSD Universitas PGRI Semarang

Jl. Sidodadi Timur No. 24, Dr. Cipto Semarang

Email: maulia.syahbarina@gmail.com

\begin{abstract}
The background of this study is based on observations and interviews with class $\vee$ teachers that students still have difficulty in understanding the letter of Java. Actions that have been done by teachers to overcome these problems have not been maximized, due to the limitations of tools and media. The type of this research is research and development with the developed product that is MONORAJA media (Monopoli Aksara Jawa) on Javanese language subject matter Java letter for elementary school student. The media were tested in 3 primary schools namely SDN Sadeng 01 Gunungpati, SDN 1 Lamuk Purbalingga, and SDN 2 Sinduraja Purbalingga. The results obtained from the validation of material experts, media experts, teacher practitioner questionnaire, and student assessment questionnaire. The result of validation by the first material expert is $97.71 \%$, the second material expert is $98.5 \%$, the validation by the media expert is $95 \%$, the practitioner is $98 \%$, and the student's appraisal is $96.36 \%$ This shows that MONORAJA media has been successful in development.
\end{abstract}

Keywords: learning media; javanese letters, MONORAJA (javanese script monopoly)

\begin{abstract}
ABSTRA
Penelitian ini dilatarbelakangi hasil observasi dan wawancara dengan guru kelas $V$ mengenai kesulitan siswa dalam memahami huruf Jawa. Beberapa kendala yang muncul diantaranya keterbatasan alat dan media. Penelitian ini merupakan Penelitian dan Pengembangan (Research and Development) yang bertujuan untuk mengembangkan suatu media pembelajaran yaitu media MONORAJA (Monopoli Aksara Jawa) pada mata pelajaran Bahasa Jawa materi huruf Jawa untuk siswa sekolah dasar. Media diujicobakan di 3 sekolah dasar yaitu SDN Sadeng 01 Gunungpati, SDN 1 Lamuk Purbalingga, dan SDN 2 Sinduraja Purbalingga. Penelitian divalidasi oleh ahli materi, ahli media, angket praktisi guru, dan angket penilaian siswa. Hasil dari validasi oleh ahli materi yang pertama yaitu sebesar $97,71 \%$, ahli materi yang kedua sebesar $98,5 \%$, validasi oleh ahli media yaitu sebesar 95\%,praktisi guru sebesar $98 \%$, dan penilaian siswa sebesar $96,36 \%$, hal ini menunjukkan bahwa media MONORAJA dapat mengatasi kesulitan siswa dalam memahami huruf jawa.
\end{abstract}

Kata Kunci: media pembelajaran; huruf jawa; MONORAJA (monopoli aksara jawa)

How to Cite: Syahbarina, M. (2017). Pengembangan Media MONORAJA (Monopoli Aksara Jawa) untuk Siswa Sekolah Dasar. Mimbar Sekolah Dasar, 4(3), 245-255. http://doi.org/10.17509/mimbar-sd.v4i3.7919.

PENDAHULUAN Indonesia merupakan negara yang kaya akan budaya, terdapat berbagai macam suku dan budaya yang tersebar di seluruh daerah. Salah satunya di daerah Jawa terdapat berbagai macam kebudayaan seperti tarian daerah, lagu daerah dan bahasa daerah. Setiap satuan pendidikan berdasarkan dengan Peraturan Gubernur Jawa Tengah
Nomor 57 Tahun 2013 Pasal 13 yang berbunyi "Semua satuan pendidikan di Jawa Tengah wajib melaksanakan Pelajaran Bahasa Jawa", wajib melaksanakan pembelajaran bahasa jawa. Tujuannya antara lain merupakan upaya menjaga dan memelihara kelestarian budaya Jawa dilakukan melalui pembelajaran Bahasa Jawa di 
Maulia Syahbarina, Pengembangan Media Monoraja (Monopoli Aksara Jawa)...

berbagai jenjang pendidikan. Selanjutnya berdasarkan Keputusan Gubernur Jawa Tengah Nomor: 423.5/5/2010 bahwa ruang lingkup mata pelajaran Bahasa Jawa ada 4 yaitu mendengarkan, membaca, berbicara dan menulis. Alokasi waktu pelajaran Bahasa Jawa untuk setiap pertemuan yaitu $2 \times 35$ menit dan hanya 1 pertemuan dalam satu minggu. Guru diharapkan dapat memaksimalkan waktu yang sudah ditentukan agar pembelajaran Bahasa Jawa dapat tersampaikan dengan baik kepada peserta didik.

Materi dalam pelajaran Bahasa Jawa salah satunya yaitu aksara Jawa. Siswa memerlukan proses belajar yang terjadi secara terus menerus, namun tetap menyenangkan agar pembelajaran dapat lebih bermakna dan pada akhirnya mereka dapat menguasai materi huruf Jawa. Upaya yang dilakukan untuk meningkatkan mutu penggunaan aksara Jawa dapat melalui pembelajaran dapat dilakukan dengan mengembangkan buku pelajaran, buku bacaan, majalah atau alat peraga Bahasa Jawa yang dapat dijalan sebagai media untuk membantu proses belajar mengajar. Mengenai hal tersebut Kustandi \& Sutjipto (2013, p. 8) menuliskan manfaat media yaitu "media pembelajaran merupakan alat yang dapat membantu proses belajar mengajar dan berfungsi untuk memperjelas makna pesan yang disampaikan, sehingga dapat mencapai tujuan pembelajaran dengan baik dan sempurna".
Daryanto (2010, p. 147) mempertegas istilah media, bahwa "kata media berasal dari bahasa Latin yang dibatasi pada pendidikan saja yakni media yang digunakan sebagai alat dan bahan kegiatan pembelajaran". Guru sebagai tenaga pendidik profesional harus dapat memilih media yang tepat untuk menunjang tercapainya tujuan pembelajaran yang diharapkan. Seperti yang dianalisis oleh Kemp dan Dayton dalam Kustandi \& Sutjipto (2013, p. 20) mengenai fungsi media. Media pembelajaran dapat memenuhi tiga fungsi utama apabila media itu digunakan untuk perorangan, kelompok, atau kelompok besar jumlahnya, yaitu dalam hal (1) memotivasi minat atau tindakan, (2) menyajikan informasi, dan memberikan instruksi. Apabila pemanfaatan media sudah tepat, maka akan tercipta pembelajaran yang bermakna sehingga hasilnya dapat meningkatkan minat belajar dan hasil belajar siswa.

Hasil wawancara dengan guru kelas $\vee$ di 3 sekolah yaitu SDN Sadeng 01 Gunungpati, SDN 1 Lamuk Purbalingga, dan SDN 2 Sinduraja Purbalingga mengindikasikan pembelajaran Bahasa Jawa, materi huruf Jawa di sekolah dasar mengalami kendala dalam keterbatasan media pembelajaran yang sesuai dengan materi huruf Jawa serta proses pembelajaran yang belum disesuaikan dengan karakteristik anak SD yang senang bermain. 
Oleh karena itu dikembangkan sebuah media pembelajaran yang membantu guru dalam menyampaikan pesan atau informasi kepada siswa. Selain mengembangkan media pembelajaran, cara yang dapat dilakukan adalah menerapkan proses belajar dengan konsep permainan, karena Menurut Baedowi (2015, P. 307) "permainan menyenangkan suasana hati sehingga anak-anak pun belajar dengan suka cita".

Salah satu permainan yang disukai anakanak, remaja, bahkan dewasa jaman sekarang adalah Get Rich. Berdasarkan berita yang dimuat secara online oleh Susanti (2015) "game ini hampir sama dengan permainan manual monopoli karena cara berjalannya mengikuti alur dadu". Oleh karena itu dilakukan penelitian pengembangan media permainan untuk pembelajaran Bahasa Jawa materi huruf Jawa dengan judul "Pengembangan Media MONORAJA (Monopoli Aksara Jawa) Pada Mata Pelajaran Bahasa Jawa Materi Huruf Jawa Untuk Siswa Sekolah Dasar".

Pengembangan MONORAJA selain dapat mengatasi keterbatasan media juga diharapkan dapat mengubah proses belajar mengajar yang dilakukan oleh guru menjadi lebih bervariasi, membuat proses pembelajaran menjadi lebih menyenangkan karena disesuaikan dengan karakteristik anak SD yang suka bermain. Hasil diskusi Falahudin (2014, P. 104) menyimpulkan bahwa "media pembelajaran dalam proses belajar mengajar dapat membangkitkan minat dan keinginan yang baru, membangkitkan motivasi dan rangsangan kegiatan belajar, dan bahkan membawa pengaruh-pengaruh psikologis terhadap pebelajar".

Permainan dalam penelitian ini dijadikan juga sebagai sarana untuk membuat proses pembelajaran lebih menarik dan menyenangkan. Banyak penelitian yang menggunakan permainan sebagai bagian penting dalam proses pembelajaran, yang membedakan dengan penelitian yang sudah ada, penelitian ini merupakan penelitian pengembangan yang bertujuan untuk menghasilkan produk media dan permainan yang bisa meningkatkan pemahaman siswa dalam berbahasa Jawa. Keunggulan dari penelitian ini adalah selain sesuai dengan budaya lokal siswa, yang memperhatikan karakter peserta didik di sekolah dasar yang memang senang bermain, bagi siswa kegiatan bermain dapat mempengaruhi perkembangan enam aspek perkembangan anak, yakni aspek kesadaran diri (personal awareness), emosional, sosial, komunikasi, kognisi, dan keterampilan motorik. Hasil Riset Smith dan Pellegrini (2008) menunjukkan bahwa bermain memenuhi 3-20\% waktu seorang anak, dan hanya anak yang sakit atau cacat yang tidak melakukan kegiatan bermain. 
Maulia Syahbarina, Pengembangan Media Monoraja (Monopoli Aksara Jawa)...

Permainan dapat dilakukan di luar kelas agar pembelajaran tidak kaku, monoton, dan siswa tidak merasa bosan sehingga siswa cepat memahami konsep materi yang diajarkan (Anggraini, 2014, p. 93). Zaman \& Libertina (2012, p. 15) menuliskan "bermain merupakan sarana uji coba pada diri anak untuk belajar interaksi". Anak akan merasa senang apabila dibebaskan untuk bermain dengan teman sebayanya. Interaksi yang menyenangkan tersebut dapat mengembangkan berbagai kemampuan anak seperti cara bertingkah laku, cara berbicara, perkembangan fisik serta pengolahan emosi.

Permainan yang dikembangkan adalah permainan monopoli. Monopoli merupakan salah satu permainan papan yang paling terkenal di dunia. Tujuan permainan ini adalah untuk menguasai semua petak di atas papan melalui pembelian, penyewaan dan pertukaran properti dalam sistem ekonomi yang disederhanakan. Setiap pemain melemparkan dadu secara bergiliran untuk memindahkan bidaknya, dan apabila ia mendarat di petak yang belum dimiliki oleh pemain lain, ia dapat membeli petak itu sesuai harga yang tertera. Bila petak itu sudah dibeli pemain lain. la harus membayar sewa yang jumlahnya juga sudah ditetapkan.

Dalam penelitian ini konsep materinya adalah materi bahasa jawa. Martulina (2015, p. 12) menuliskan "bahasa sebagai alat komunikasi merupakan saluran perumusan maksud individu, melahirkan perasaan individu dan memungkinkan individu menciptakan kerja sama dengan sesama individu". Pada zaman dahulu kelompok orang Jawa yang tinggal di Belanda, di samping mereka menggunakan bahasa Belanda juga tetap menggunakan bahasa Jawa di antara kelompoknya Wedhawati dkk. (2006, P. 24). Oleh karena itu, sudah semestinya kebudayaan tersebut terus dilestarikan agar tidak terlupakan oleh adanya perkembangan jaman.

Menurut Surat Keputusan Menteri Pendidikan dan Kebudayaan Republik Indonesia dengan nomor 0412/U/1987 tanggal 11 Juli 1987 yang dimaksud dengan kurikulum muatan lokal ialah program pendidikan yang isi dan media penyampaiannya dikaitkan dengan lingkungan alam dan lingkungan budaya serta kebutuhan daerah dan wajib dipelajari oleh murid di daerah tersebut.

\section{METODE}

Jenis penelitian yang digunakan adalah penelitian dan pengembangan (Research and Development). Penelitian ini dilakukan untuk mengembangkan media MONORAJA. Harapannya media MONORAJA dapat menjadi inovasi dalam proses pembelajaran sehingga dapat meningkatkan mutu pendidikan. Soegeng (2016, pp. 212-213) menguraikan "penelitian pengembangan 
(Development Research $=D R)$ dilakukan untuk mengembangkan suatu produk yang akan digunakan dalam proses pembelajaran". Hal yang sama ditulis oleh Sugiyono (2015, p. 407) bahwa "metode penelitian dan pengembangan atau dalam bahasa Inggrisnya Research and Development adalah metode penelitian yang digunakan untuk menghasilkan produk tertentu, dan menguji keefektifan produk tersebut". Penelitian dan pengembangan bertujuan untuk: (1) mengembangkan produk yang sudah ada, dan (2) juga untuk menemukan produk baru sebagai jawaban (pemecahan) masalah-masalah praktis pendidikan (Soegeng, 2016, p. 222). Model pengembangan yang digunakan adalah pengembangan yang dikemukakan oleh Borg and Gall. Menurut Borg and Gall ada 10 langkah yang dikemukakan dalam penelitian dan pengembangan (Soegeng, 2016, p. 226). Tahapan tersebut dapat digambarkan dalam sebuah penggambaran dari tahapan awal kondisi hingga tahap paling akhir. Penelitian dilaksanakan di 3 sekolah dasar yaitu SDN Sadeng 01 Gunungpati, SDN 1 Lamuk Purbalingga, dan SDN 2 Sinduraja Purbalingga. Langkah/prosedur penelitian pengembangan mengacu pada pendapat Borg \& Gall (1983, p. 775) yang mengembangkan 10 tahapan dalam mengembangkan model, dari 10 tahapan pengembangan menurut Borg and Gall tersebut peneliti membatasi langkah penelitian hanya sampai tahap ke 5 yaitu merevisi hasil uji coba berdasarkan analisis uji coba lapangan awal.

Studi pendahuluan dilakukan dengan melakukan observasi dan wawancara kepada guru Sekolah Dasar yaitu SDN Sadeng 01, SDN 1 Lamuk, dan SDN 2 Sinduraja pada bulan Oktober 2016. Angket analisis kebutuhan guru dan siswa diberikan untuk mendapatkan data berkaitan pembelajaran Bahasa Jawa materi huruf Jawa.

\section{HASIL DAN PEMBAHASAN}

Berdasarkan hasil observasi dan wawancara yang dilakukan terhadap 3 sekolah yaitu SDN Sadeng 01 Gunungpati, SDN 1 Lamuk Purbalingga, dan SDN 2 Sinduraja Purbalingga, diperoleh informasi bahwa siswa mengalami kesulitan pada saat pembelajaran Bahasa Jawa materi huruf Jawa. Siswa mengalami kesulitan dalam mengerjakan soal yang berkaitan dengan huruf Jawa, hal tersebut dikarenakan siswa kurang memahami huruf Jawa. Kesulitan siswa yaitu menghafal huruf Jawa sehingga akan merasa kesulitan apabila mendapatkan soal yang berkaitan dengan membaca dan menulis huruf Jawa. Pembelajaran Bahasa Jawa yang dilakukan selama $2 \times$ 35 menit dalam seminggu dirasa kurang untuk membuat anak terampil dalam membaca dan menulis huruf Jawa.

Pada proses pembelajaran terkadang guru menggunakan media sebagai penunjang dalam memudahkan 
Maulia Syahbarina, Pengembangan Media Monoraja (Monopoli Aksara Jawa)...

penyampaian materi, namun media tersebut cukup terbatas yaitu hanya sebuah panduan huruf Jawa yang ditempel di dinding kelas. Buku yang digunakan adalah buku pegangan guru atau buku paket paket dan LKS yang sama dengan yang dimiliki oleh siswa.

Sebelum membuat media MONORAJA peneliti menyebar angket analisis kebutuhan siswa dalam mata pelajaran Bahasa Jawa materi huruf Jawa untuk kelas $\vee$ sekolah dasar agar peneliti mengetahui media seperti apa yang diharapkan dan dibutuhkan oleh siswa.

Media MONORAJA adalah sebuah media pembelajaran yang di kembangkan dari sebuah permainan monopoli. Permainan monopoli pada umumnya yaitu bermain dengan cara melemparkan dadu secara bergiliran untuk memindahkan bidaknya, dan apabila ia mendarat di petak yang belum dimiliki oleh pemain lain, ia dapat membeli petak itu sesuai harga yang tertera.

Permainan monopoli pada umumnya oleh peneliti dikembangkan menjadi sedemikian rupa dengan desain dan tampilan yang berbeda yaitu terdiri dari 24 petak dan terdapat kartu soal yang berkaitan dengan huruf Jawa. Kartu soal tersebut dibuat menjadi 4 tingkatan disesuaikan dengan SK dan KD pada mata pelajaran Bahasa Jawa materi huruf Jawa untuk siswa kelas III, IV, V, dan VI, sehingga tingkat 1 diperuntukkan untuk siswa kelas III, tingkat 2 untuk siswa kelas IV, tingkat 3 untuk siswa kelas IV, dan tingkat $\checkmark$ untuk siswa kelas VI. Media MONORAJA ini dibuat dari bahan kayu sehingga awet untuk digunakan. Media ini juga praktis dan mudah untuk di bawa karena didesain berbentuk kotak yang dapat dilipat dan bagian dalamnya digunakan untuk menyimpan alat-alat permainan.

Draf media MONORAJA divalidasi oleh ahli media dan ahli materi pembelajaran. Ahli media pembelajaran Bapak Singgih Adhi Prasetyo, S.Sn., M.Pd. dosen Universitas PGRI Semarang, untuk ahli materi Bapak Drs. Suyitno Y.P., M.Pd. dosen Universitas PGRI Semarang, dan Bapak Sugeng Hastopo, S.Pd.SD kepala sekolah SDN 1 Lamuk Purbalingga, sedangkan data mengenai penilaian praktisi (guru) disajikan melalui angket yang diisi oleh guru kelas V, serta tanggapan siswa angket yang disajikan berupa pernyataan dengan jawaban "ya" atau "tidak" dalam bentuk skala Guttman. Sebagai bahan evaluasi, peneliti juga memberikan tes evaluasi yang terdiri dari 10 soal esai sebagai tolak ukur dan menargetkan hasil tes semua siswa diatas KKM yaitu 65.

Proses validasi dilakukan oleh ahli materi pertama yaitu Drs. Suyitno Y.P, M.Pd. dosen prodi PGSD, Fakultas IImU Pendidikan, Universitas PGRI Semarang. Validasi materi dilakukan terhadap tiga indikator, yaitu Indikator Kompetensi, Indikator Penggunaan Konsep, dan Indikator Manfaat produk. Validasi 
dilakukan dengan memberikan data kuantitatif sebagai penilaian kemudian ahli materi memberikan saran untuk perbaikan. Validasi materi yang pertama lakukan tanggal 23 Maret 2017.

Tabel 1. Hasil Penilaian Ahli Materi Pertama Tahap 1 Media MONORAJA

\begin{tabular}{llccc}
\hline No & Indikator & $\begin{array}{c}\text { Jumlah } \\
\text { Skor }\end{array}$ & $\begin{array}{c}\text { Skor } \\
\text { Ideal }\end{array}$ & Persentase \\
\hline 1. & Kompetensi & 23 & 25 & $\frac{23}{25} \times 100 \%=92,00 \%$ \\
\hline 2. & Penggunaan konsep & 12 & 15 & $\frac{12}{15} \times 100 \%=80,00 \%$ \\
\hline 3. & Manfaat produk & 30 & 30 & $\frac{30}{30} \times 100 \%=100 \%$ \\
\hline & Jumlah & 65 & 70 & $\frac{65}{70} \times 100 \%=92,85 \%$ \\
\hline
\end{tabular}

Tabel 2. Hasil Penilaian Ahli Materi Pertama Tahap 2 Media MONORAJA

\begin{tabular}{llccc}
\hline No & Indikator & $\begin{array}{c}\text { Jumlah } \\
\text { Skor }\end{array}$ & $\begin{array}{c}\text { Skor } \\
\text { Ideal }\end{array}$ & Persentase \\
\hline 1. & Kompetensi & 25 & 25 & $\frac{25}{25} \times 100 \%=100 \%$ \\
\hline 2. & Penggunaan Konsep & 12 & 15 & $\frac{12}{15} \times 100 \%=80,00 \%$ \\
\hline 3. & Manfaat Produk & 30 & 30 & $\frac{30}{30} \times 100 \%=100 \%$ \\
\hline & Jumlah & 67 & 70 & $\frac{67}{70} \times 100 \%=97,71 \%$ \\
\hline
\end{tabular}

Berdasarkan Tabel 2 dapat dipahami bahwa media MONORAJA mendapat nilai 97,71\%. Hal ini menunjukkan bahwa media MONORAJA menurut ahli materi pertama sudah layak digunakan tanpa revisi.

Validasi ahli materi kedua dilakukan oleh Bapak Sugeng Hastopo, S.Pd.SD kepala SDN 1 Lamuk Purbalingga. Validasi materi dilakukan terhadap tiga indikator, yaitu Indikator Kompetensi, Indikator Penggunaan Konsep, dan Indikator Manfaat produk. Validasi dilakukan dengan memberikan data kuantitatif sebagai penilaian kemudian ahli materi memberikan saran untuk perbaikan.

Validasi dilakukan dengan memberikan data kuantitatif sebagai penilaian kemudian ahli materi memberikan saran untuk perbaikan. Validasi materi dilakukan pada tanggal 25 Maret 2017. Hasil validasi materi yang kedua tahap 1 sebagaimana terlihat pada tabel 3, dapat dijelaskan sebagai berikut. Jumlah skor pada indikator kompetensi yaitu 24 dari skor ideal 25, sehingga persentasenya adalah 96\%. Pada indikator penggunaan konsep jumlah skor yang didapatkan yaitu 15 dari 
Maulia Syahbarina, Pengembangan Media Monoraja (Monopoli Aksara Jawa)...

skor ideal 15, sehingga persentasenya 100\%. Pada indikator manfaat produk jumlah skor yang didapatkan yaitu 30 dari skor ideal 30, sehingga persentasenya 100. Berdasarkan penilaian tersebut dapat didapatkan jumlah skor keseluruhan 69, dari skor ideal 70, sehingga persentase keseluruhan adalah 98,5\%. Hal tersebut menunjukkan media MONORAJA sudah layak untuk digunakan sebagai media pembelajaran. dosen prodi PGSD, Fakultas IImu Pendidikan, Universitas PGRI Semarang.

Tabel 3. Hasil Penilaian Ahli Materi Kedua Tahap 1 Media MONORAJA

\begin{tabular}{llccc}
\hline No & Indikator & $\begin{array}{c}\text { Jumlah } \\
\text { Skor }\end{array}$ & $\begin{array}{c}\text { Skor } \\
\text { Ideal }\end{array}$ & Persentase \\
\hline 1. & Kompetensi & 24 & 25 & $\frac{24}{25} \times 100 \%=96 \%$ \\
\hline 2. & Penggunaan Konsep & 15 & 15 & $\frac{15}{15} \times 100 \%=100 \%$ \\
\hline 3. & Manfaat Produk & 30 & 30 & $\frac{30}{30} \times 100 \%=100 \%$ \\
\hline & Jumlah & 69 & 70 & $\frac{69}{70} \times 100 \%=98,5 \%$ \\
\hline
\end{tabular}

Validasi media dilakukan terhadap tiga indikator, yaitu Indikator Desain Produk, Kualitas Produk, dan Teknik Penggunaan. Selanjutnya dilakukan Validasi ahli media oleh Singgih Adhi Prasetyo, S.Sn., M.Pd. Validasi dilakukan dengan memberikan data kuantitatif sebagai penilaian kemudian ahli mediamemberikan saran untuk perbaikan. Validasi media dilakukan pada tanggal 23 Maret 2017. Hasil validasi media tahap 1 sebagaimana terlihat pada tabel 4 adalah sebagai berikut. Jumlah skor pada indikator desain produk yaitu 36, dari skor ideal 40, sehingga persentasenya adalah 90,00\%. Pada indikator kualitas produk jumlah skor yang didapatkan yaitu 23, dari skor ideal 25, sehingga persentasenya 92,00\%. Pada indikator teknik penggunaan jumlah skor yang didapatkan yaitu 15 dari skor ideal 15, sehingga persentasenya $100 \%$. Berdasarkan penilaian tersebut dapat keseluruhan adalah 95\%. Hal tersebut menunjukkan media MONORAJA sudah layak untuk digunakan sebagai media pembelajaran tanpa revisi.

Tabel 4.Hasil Penilaian Angket Ahli Media Tahap 1 Media MONORAJA

\begin{tabular}{llccc}
\hline No & Aspek Penilaian & $\begin{array}{c}\text { Jumlah } \\
\text { Skor }\end{array}$ & $\begin{array}{c}\text { Skor } \\
\text { ldeal }\end{array}$ & Persentase \\
\hline 1. & Desain Produk & 36 & 40 & $\frac{36}{40} \times 100 \%=90,00 \%$ \\
\hline 2. & Kualitas Produk & 23 & 25 & $\frac{23}{25} \times 100 \%=92,00 \%$ \\
\hline
\end{tabular}




\begin{tabular}{cccl}
\hline 3. Teknik Penggunaan & 15 & 15 & $\frac{15}{15} \times 100 \%=100 \%$ \\
\hline Jumlah & 76 & 80 & $\frac{76}{80} \times 100 \%=95,00 \%$ \\
\hline
\end{tabular}

Hasil pembelajaran Bahasa Jawa menggunakan media MONORAJA dapat di katakan berhasil karena hasil evaluasi siswa memenuhi di atas KKM yaitu 65. Siswa mendapat nilai yang bagus dan dapat di katakan sangat baik dikarenakan nilai rata-rata yang tinggi.

Berdasarkan hasil tes ujicoba nilai rata-rata siswa yaitu 86, 81. Hal tersebut menunjukkan siswa dapat memahami materi huruf Jawa. Soal evaluasi yang berjumlah 10 telah disesuaikan dengan KD membaca dan menulis huruf Jawa di kelas V. Soal disusun dari tingkat yang mudah hingga yang sulit dan terbukti siswa mampu mengerjakan soal dengan benar. Hasil tersebut sesuai dengan target yang ingin dicapai oleh peneliti. Siswa dapat mengikuti pembelajaran dengan baik terlihat dari hasil belajar siswa yang baik. Selain itu, saat uji coba kepada siswa terdapat respon yang baik terhadap media MONORAJA. Hasil penelitian tersebut memiliki kesesuaian dengan hasil penelitian yang dilakukan oleh Oktavianti (2014, p.76) bahwa "Penggunaan media pembelajaran pada tahap orientasi pembelajaran akan sangat membantu keefektifan proses pembelajaran dan penyampaian pesan dan isi pelajaran saat itu".
Hasil angket penilaian media MONORAJA yang dibagikan kepada siswa untuk mengetahui seberapa besar minat siswa terhadap pengembangan media MONORAJA yang telah dibuat, dari 44 jumlah responden atau siswa yang menjawab "ya" sebanyak 96,36\%. Dari hasil itu dapat disimpulkan bahwa media MONORAJA merupakan media yang dapat digunakan dalam pembelajaran Bahasa Jawa materi huruf Jawa.

Selain penilaian dilakukan oleh siswa, MONORAJA juga dinilai oleh praktisi yaitu guru kelas V. Guru diberikan angket penilaian yang bertujuan untuk mengukur seberapa praktis dan diterimanya media pembelajaran MONORAJA dalam pembelajaran Bahasa Jawa. Berdasarkan analisis angket praktisi media terhadap media pembelajaran MONORAJA yang telah diisi oleh 3 guru dari masing-masing sekolah maka diperoleh skor sebanyak 147 dari jumlah skor maksimal sebanyak 150. Dari skor tersebut dapat diperoleh persentase rata-rata sebesar $98 \%$ dengan kategori sangat baik. Hal ini membuktikan bahwa guru kelas $V$ merasa senang dan memberikan tanggapan positif terhadap media MONORAJA.

Yang perlu diperhatikan bahwa dalam menciptakan pembelajaran bermutu seluruh komponen yang terlibat dalam 
Maulia Syahbarina, Pengembangan Media Monoraja (Monopoli Aksara Jawa)...

pembelajaran termasuk di antaranya media pembelajaran harus benar-benar direncananakan serta dikelola dengan baik, dengan begitu akan memungkinkan terjadinya interaksi pembelajaran yang kondusif dan pada akhirnya berkualitas karena semua informasi atau pesan mampu diterima oleh siswa Sunaengsih (dalam Sagala, 2010)

\section{SIMPULAN}

Pengembangan media pembelajaran MONORAJA menggunakan model pengembangan yang dikemukakan oleh Borg and Gall.Dari 10 tahap peneliti membatasi langkah penelitian hanya sampai tahap ke 5merevisi hasil uji coba berdasarkan analisis uji coba lapangan awal. Media MONORAJA telah divalidasi oleh 3 ahli yaituhasil dari validasi oleh ahli materi pertama sebesar $97,71 \%$, dan ahli materi yang kedua sebesar 98,5\%, sedangkan validasi oleh ahli media sebesar 95\%. Sehingga dapat disimpulkan MONORAJA valid dan dapat diujicobakan dalam pembelajaran Bahasa Jawa materi huruf Jawa di sekolah. Media MONORAJA diujicobakan di SDN sadeng 01 Gunungpati, SDN 1 Lamuk Purbalingga, SDN 2 Sinduraja Purbalingga. Berdasarkan angket penilaian siswa terhadap media setelah mengikuti pembelajaran dari 44 siswa kelas $V$ didapatkan data $96,36 \%$ siswa menjawab "ya". Sedangkan angket praktisi guru yang diberikan kepada guru kelas $\vee$ di 3 sekolah didapatkan data $98 \%$ guru menyatakan media MONORAJA praktis dan diterima untuk digunakan sebagai media pembelajaran Bahasa Jawa materi huruf Jawa.

\section{REFERENSI}

Falahudin, I. (2014). PEMANFAATAN MEDIA DALAM PEMBELAJARAN. Jurnal Lingkar Widyaiswara (www.juliwi.com) Edisi 1 No. 4, Oktober - Desember 2014, p.104 $-117$.

Anggraini, C., \& Untari, M. (2014). KEEFEKTIFAN MODEL PERMAINAN BOYBOYAN TERHADAP HASIL BELAJAR TEMA "DIRIKU" SISWA KELAS I SD. Mimbar Sekolah Dasar, 1(1), 92-98. doi:http://dx.doi.org/10.17509/mimbarsd.viil.869.

Smith, Peter $\mathrm{K}$ And Pellegrini, Antony. (2008). "Learning Through Play". Minessta: Goldsmiths, University of London, United Kingdom University of Minnesota, USA (Published online September 12, 2008).

Borg. W.R. dan Gall, M.D. (1983). Educational Research: An Introduction. New York: longman.

Baedowi, A dkk. (2015). Potret Pendidikan Kita. Jakarta: PT Pustaka Alfabet.

Daryanto.(2010). Media Pembelajaran Peranannya Sangat Penting Dalam Mencapai Tujuan Pembelajaran. Yogyakarta: Gava Media.

Kustandi, Cecep dan Bambang S. (2013). Media Pembelajaran; Manual dan Digital. Bogor: Ghalia Indonesia.

Martulina, S, D. (2015). Bahasa Indonesia Terapan. Yogyakarta: CV Budi Utama.

Oktavianti, R., \& Wiyanto, A. (2014). PENGEMBANGAN MEDIA GAYANGHETUM (GAMBAR WAYANG HEWAN DAN TUMBUHAN) DALAM PEMBELAJARAN TEMATIK TERINTEGRASI KELAS IV SD. Mimbar Sekolah Dasar, 1(1). $\quad$ 65-70. doi:http://dx.doi.org/10.17509/mimbarsd.vli1.865 
Soegeng, A,Y. (2016). Dasar-Dasar Penelitian Bidang Sosial, Psikologi, dan Pendidikan. Yogyakarta: Magnum Pustaka Utama.

Sugiyono. (2015). Metode Penelitian Pendidikan (Pendekatan Kuantitatif, Kualitatif, dan $R$ \& D). Bandung: Alfabeta.

Sunaengsih, C. (2016). PENGARUH MEDIA PEMBELAJARAN TERHADAP MUTU PEMBELAJARAN PADA SEKOLAH DASAR TERAKREDITASI A.Mimbar Sekolah Dasar, 3(2), $\quad$ 183-190. doi:http://dx.doi.org/10.23819/mimbarsd.v3i2.4259

Surat Keputusan Gubernur Jawa Tengah Nomor: 423.5/5/2010 tentang Kurikulum Mata Pelajaran Muatan Lokal (Bahasa Jawa) untuk Jenjang Pendidikan SD/SDLB/MI,SMP/SMPLB/MTs Negeri dan Swasta Propinsi Jawa Tengah.

Surat Keputusan Menteri Pendidikan dan Kebudayaan Republik Indonesia dengan nomor 0412/U/1987 tanggal 11 Juli 1987 Tentang Kurikulum Muatan Lokal.

Susanti, E. (2015). "Aplikasi Game Android Gratis, Terbaik, Terpopuler, dan Terbaru 2015".

www.teknoflas.com/24168/aplikasigame-android-gratis-terbaik-terpopulerdan-terbaru-2015.html. Teknoflas. Diakses 01 November 2016.

Wedhawati dkk. (2006). Tata Bahasa Jawa Muthakhir. Yogyakarta: Kanisius.

Zaman, Saeful dan Aundriani L. (2012). Membuat Anak Rajin Belajar Itu Gampang. Jakarta: Visimedia. 